DR LARA EVELIINA LEHTORANTA (Orcid ID : 0000-0001-8325-2411)

PROFESSOR JUHA RÄSÄNEN (Orcid ID : 0000-0002-3868-5936)

Article type : Original Research Article

\title{
Fetal cardiovascular hemodynamics in type 1 diabetic pregnancies at near term gestation
}

Lara Lehtoranta $^{1,2,3}$; Mervi Haapsamo ${ }^{2,4}$; Olli Vuolteenaho ${ }^{2}$; Pertti Palo ${ }^{1}$; Eeva Ekholm¹; Juha Räsänen ${ }^{5}$

${ }^{1}$ Department of Obstetrics and Gynecology, University of Turku, and Turku University Hospital, Turku, Finland; ${ }^{2}$ Institute of Biomedicine, Department of Physiology, University of Oulu, Oulu, Finland; ${ }^{3}$ The Research Centre of Applied and Preventive Cardiovascular Medicine (CAPC), University of Turku, Turku, Finland; ${ }^{4}$ Satakunta Central Hospital, Pori, Finland; ${ }^{5}$ Fetal Medicine Center, Department of Obstetrics and Gynecology, Helsinki University Hospital and University of Helsinki, Helsinki, Finland

\section{Corresponding author:}

Lara Lehtoranta

University of Turku, Department of Obstetrics and Gynecology, Kiinamyllynkatu 13, 20520

Turku, Finland

Email: lara.lehtoranta@utu.fi

\section{Conflicts of interest}

The authors report no conflict of interest

This article has been accepted for publication and undergone full peer review but has not been through the copyediting, typesetting, pagination and proofreading process, which may lead to differences between this version and the Version of Record. Please cite this article as doi: 10.1111/AOGS.13987

This article is protected by copyright. All rights reserved 


\section{Funding}

This study was supported by grants from The Diabetes Research Foundation of The Finnish

Diabetes Association, The Turku University Hospital Research Foundation, and The National Graduate School of Clinical Investigation.

This article is protected by copyright. All rights reserved 


\section{ABSTRACT}

Introduction: Poor glycemic control in maternal type 1 diabetes mellitus during pregnancy can affect fetal cardiac and placental function. However, studies concerning fetal central hemodynamics have revealed conflicting results. We hypothesized that in pregnancies complicated by maternal type 1 diabetes, fetal cardiovascular and placental hemodynamics are comparable to the control fetuses at near term gestation. In addition, we investigated the relationship between newborn serum biomarkers of cardiac function and fetal cardiovascular and placental hemodynamics. Furthermore, we studied, whether maternal diabetes is associated with placental inflammation. Material and methods: In this prospective case-control study, fetal central and peripheral hemodynamics were assessed by ultrasonography in 33 women with type 1 diabetes and in 67 controls with singleton pregnancies between $34+2$ and $40+2$ gestational weeks. Newborn umbilical cord serum was collected to analyze cardiac natriuretic peptides (atrial and Btype natriuretic peptides) and troponin T concentrations. Placental tissue samples were obtained for cytokine analyses. Results: Fetal ventricular wall thicknesses were greater and weight-adjusted stroke volumes and cardiac outputs were lower in the type 1 diabetes group than in the control group. Pulsatility in the aortic isthmus and inferior vena cava blood flow velocity waveforms was greater in the type 1 diabetes group fetuses than in the controls. A positive correlation was found between branch pulmonary artery and aortic isthmus pulsatility index values. Umbilical artery pulsatility indices were comparable between the groups. Umbilical cord serum natriuretic peptide and troponin $\mathrm{T}$ concentrations were elevated in the type 1 diabetes fetuses. These cardiac biomarkers correlated significantly with cardiovascular hemodynamics. Placental cytokine levels were not different between the groups. Conclusions: In maternal type 1 diabetes pregnancies, fetal cardiovascular hemodynamics is impaired. Maternal type 1 diabetes does not seem to alter placental vascular impedance or induce placental inflammation.

\section{Keywords:}

aortic isthmus, branch pulmonary artery, cardiac dysfunction, Doppler ultrasound, natriuretic peptide, placenta, type 1 diabetes 


\section{Abbreviations:}

ANP, atrial natriuretic peptide

BNP, B-type natriuretic peptide

E/A-ratio, ratio of velocity-time integrals of early ventricular filling and atrial contraction gHbA1c, glycated hemoglobin

IL, interleukin

NT-proANP, N-terminal peptide of proatrial natriuretic peptide

NT-proBNP, N-terminal peptide of proB-type natriuretic peptide

T1DM, type 1 diabetes mellitus

$\mathrm{TnT}$, cardiac troponin $\mathrm{T}$

\section{Key message}

In pregnancies complicated by maternal type 1 diabetes, fetal cardiovascular hemodynamics is impaired. Maternal type 1 diabetes does not seem to affect placental vascular impedance or induce placental inflammation. 


\section{INTRODUCTION}

Maternal hyperglycemia results in fetal hyperglycemia causing excess fetal pancreatic $\beta$ cell growth. ${ }^{1}$ Hyperinsulinemia has anabolic and mitogenic effects, and increases circulating growth factor levels. ${ }^{2}$ Fetal sheep studies have shown that increased arterial blood pressure combined with elevated circulating insulin-like growth factor, natriuretic peptide, and angiotensin II concentrations increase fetal cardiac growth. ${ }^{3}$ Newborns of mothers with type 1 diabetes mellitus (T1DM) have elevated cord serum levels of natriuretic peptides, ${ }^{4}$ cardiac troponin T (TnT), ${ }^{5}$ angiotensin II, ${ }^{6}$ and growth factors. ${ }^{2}$ Increased umbilical cord serum concentrations of atrial (ANP) and B-type natriuretic peptides (BNP) and TnT correlate with increased levels of maternal glycated hemoglobin $(\mathrm{gHbA1c})^{4}$ suggesting that poor maternal glucose control can affect fetal heart.

In pregnancies complicated by maternal T1DM, the incidence of stillbirth is 4-fold and neonatal mortality 2 -fold when compared to pregnancies of healthy women. ${ }^{7}$ Fetal demise is thought to result from intrauterine hypoxia. Fetal hyperglycemia and hyperinsulinemia increase basal metabolic activity and oxygen consumption. ${ }^{8}$ In maternal T1DM pregnancies, placental histology reveals reduced villous membrane diffusion capacity, further enhancing susceptibility to hypoxemia. ${ }^{9}$ Furthermore, villous immaturity and other placental abnormalities correlate to umbilical cord insulin-like growth factor 1 levels. ${ }^{10}$ Additionally, inflammatory mediators are found in placentas of experimental models of maternal hyperglycemia ${ }^{11}$ that may further exacerbate placental oxygen delivery to the fetus.

Surveillance of fetal hemodynamics with Doppler ultrasound reduces perinatal morbidity in high-risk pregnancies, such as maternal T1DM. ${ }^{12}$ Studies on fetal cardiac function in maternal T1DM pregnancies have revealed conflicting results. ${ }^{13,14}$ Increased myocardial wall thicknesses have been reported and the wall thickness seems to correlate with circulating cord blood insulinlike growth factor-1 levels. ${ }^{15}$ Good maternal glucose control in early pregnancy is critical, since biochemical markers of fetal cardiac dysfunction at birth are increased in pregnancies with poor glycemic control in the first trimester. ${ }^{16}$ In late term fetuses of maternal T1DM, the pulsatility of umbilical artery blood flow velocity waveform that reflects the capacity of placental tertiary villous arterioles, is decreased in macrosomic fetuses. ${ }^{17}$ However, if maternal glycemic control is poor or diabetes is associated with vasculopathies, pulsatility of umbilical artery blood flow velocity waveform can be increased. ${ }^{4}$ 
We hypothesized that, in T1DM pregnancies, fetal cardiovascular and placental hemodynamics are comparable to the control group fetuses at near term gestation. In addition, we investigated newborn umbilical cord serum biochemical markers of cardiac function and their correlation with cardiovascular hemodynamic parameters. Finally, we explored whether maternal T1DM is associated with placental inflammation.

\section{MATERIAL AND METHODS}

\section{Study population}

This prospective case-control study was carried out at Turku and Oulu University Hospitals, Finland between 2006-2008. For this study, a total of 33 T1DM and 67 healthy women (control group) were included. The women with T1DM were recruited consecutively at the University Hospital outpatient maternity clinics during their first visit. Briefly, a research nurse informed women about this research project and women interested in participating in this study contacted the principal investigator. None of the diabetic women who met the inclusion criteria declined to participate in this study. For the control group, women were recruited at the outpatient maternity clinics. Again, a research nurse provided information about the study and the women were invited to contact the principal investigator. From those women who met the inclusion criteria, only one woman declined to participate in this study. Inclusion criteria for all were age $<$ 35 years, singleton pregnancy and a normal fetal anatomic survey at around 20 weeks of gestation, and for the control group women body mass index $<30$, no major serious illnesses and a normal 2hour oral glucose tolerance test at 24-28 gestational weeks. Obese women were excluded from the control group since hyperglycemia and insulin resistance often complicate these pregnancies.

Diabetic women had a combination therapy of rapid-acting aspart insulin (NovoRapid) and long-acting human insulin (Protaphane) or detemir insulin (Levemir). Two women had a continuous glucose monitoring system with rapid-acting insulin. Diabetic women were seen by a perinatologist and endocrinologist every 6-8 weeks during the first and second trimesters, and every 2-4 weeks in the third trimester. At each visit maternal gHbA1c levels were determined.

All women signed an informed consent form. Gestational age was confirmed by ultrasonography at the end of the first trimester. Maternal and neonatal outcome parameters were obtained from the hospital records. 


\section{Ultrasonography}

Transabdominal ultrasound imaging (Acuson Sequoia 512, Mountain View, CA, USA) was performed with an 8-MHz convex transducer (M.H., L.L.). The ultrasonographic data collected closest to the delivery, between $34+2$ and $40+2$ gestational weeks, was used for this study. The high pass filter was set at a minimum. An angle of $\leq 20$ degrees between the vessel and the Doppler beam was considered acceptable. The mean value from three consecutive cardiac cycles was used for further analysis. Mechanical and thermal indices were kept $<1.0$. Pulsed- and color-Doppler examinations were videotaped and analyzed offline.

Image-directed pulsed and color-Doppler was used to record mitral and tricuspid valve blood flow velocity waveforms from the four-chamber view of the heart. Velocity-time integral ratio between early ventricular and atrial contraction filling (E/A-ratio) was calculated to estimate cardiac diastolic function. The outflow blood flow velocity waveforms were recorded at the level of pulmonary and aortic valves. The valve diameters were measured using the leading-edge-toleading-edge method in systole. The cross-sectional area of the valve was calculated. Velocitytime integral was obtained by planimetering the area of the Doppler spectrum. Volume blood flows across the aortic and pulmonary valves were calculated (cross-sectional area $\mathrm{x}$ velocity-time integral $\mathrm{x}$ fetal heart rate). Left and right ventricular stroke volumes, and cardiac outputs were indexed for fetal weight. The sum of left and right ventricular cardiac outputs equal combined cardiac output. Left ventricular isovolumic relaxation and contraction times were measured and their proportions $(\%)$ of the total cardiac cycle were calculated. Global left ventricular function was estimated by calculating the index of myocardial performance ([isovolumic contraction time + isovolumic relaxation time] / ejection time). ${ }^{18}$

M-mode recordings were obtained from a four-chamber view to measure the ventricular wall and interventricular septal thicknesses at the atrioventricular valve level. End-diastolic measurements were taken at maximal chamber dilatation.

The blood flow velocity waveforms of the umbilical artery, descending aorta, ductus arteriosus, aortic isthmus, middle cerebral artery, proximal right or left branch pulmonary artery, inferior vena cava, ductus venosus and pulmonary vein were obtained, and pulsatility index [(peak systolic velocity - end-diastolic velocity)/ time-averaged maximum velocity over the cardiac cycle] and pulsatility index for veins [(peak systolic velocity-velocity during atrial contraction)/time-averaged maximum velocity over the cardiac cycle] values were calculated. Fetal heart rate was measured from the UA blood flow velocity waveform. 
Intra- and interobserver variabilities were calculated for left ventricular stroke volume by analyzing the blood flow velocity waveforms from measurements on the same patient by two researchers (MH and LL) and twice by the same researcher (LL). In addition, interobserver variability for ductus venosus blood flow velocity waveform was calculated.

\section{Newborn blood samples}

Immediately after delivery, umbilical cord blood samples were collected. Newborn umbilical artery acid base status was determined. Cardiac ANP and BNP are initially synthesized as inactive prohormones, and cleaved in equimolar amounts to ANP and BNP and inactive Nterminal peptides of proANP and proBNP (NT-proANP, NT-proBNP) respectively. Umbilical cord serum concentrations of NT-proANP and NT-proBNP were measured by radioimmunoassays. ${ }^{19}$ The sequences recognized by NT-proANP and NT-proBNP antisera were $\operatorname{proANP}_{46-79}$ and proBNP ${ }_{10-29}$. Detection limit for NT-proANP and NT-proBNP were $60 \mathrm{pmol} / 1$ and $40 \mathrm{pmol} / \mathrm{l}$. Troponin $\mathrm{T}(\mathrm{TnT})$ concentration was measured by electrochemiluminescence immunoassay (TYKSLAB, Turku, Finland). The detection limit was set at $<0.014 \mathrm{ng} / \mathrm{ml}$.

\section{Placental samples}

Placental tissue samples were collected within 2 hours after delivery and samples from diabetic pregnancies were paired with a sample of a control placenta of similar gestational age $( \pm 4$ days). Samples were stored at $-80^{\circ} \mathrm{C}$ until analysis.

Cytokine levels were measured from 24 T1DM and 25 control placental samples. The concentrations of interleukins (IL) $1 \beta$, IL6, IL10, and tumor necrosis factor alfa (TNF $\alpha$ ) (Bio-Plex Pro Human Cytokine 8-Plex Immunoassay, Bio-Rad, Hercules, CA) were considered as markers of placental inflammation. The assay was performed according to the manufacturer's instructions using Bio-Plex MAGPIX Multiplex Reader in duplicate.

\section{Statistical analyses}

The data was tested for normality. When required by the statistical distribution, a logarithmic scale or $\sqrt{ } \mathrm{x}$ conversion was utilized. Two-way comparisons were performed by Student's T-test. The categorical variables were tested for significance using Mantel-Haenszel chisquare or Fisher's exact test (for variables with less than 5 entries) method. All correlations were 
tested with Pearson's correlation ( $\mathrm{R}[\mathrm{X}=\mathrm{n}-2$, degrees of freedom]). The statistical analyses were performed using SAS (SAS Institute, Cary, NC). The level of significance was set at $\mathrm{p}<0.05$.

\section{Ethical approval}

The Ethics Committee in the Hospital Districts approved the research protocol (license 167/2005 $\S 183$, dated May 17, 2005).

\section{RESULTS}

Women with T1DM had more often hypertension, thyroid dysfunction, and preeclampsia. In the T1DM group, the median gHbA1c concentration decreased from prepregnancy level of 7.6 $\%$ to $6.5 \%$ in the early third trimester (Table 1 ).

The ultrasound examination was performed at $250( \pm 13)$ gestational days in T1DM group and at $262( \pm 13)$ days in the controls. The mean time interval from the ultrasound examination to delivery was comparable between the groups, $12( \pm 10)$ and $14( \pm 8)$ days for the T1DM and control groups. Mothers with T1DM had more often labor induction or cesarean section prior to 37 gestational weeks. There was no difference in the umbilical artery $\mathrm{pH}$ values between the groups. The incidence of large for gestational age newborns (birth weight $\geq+2$ SD) was higher, and the need of phototherapy due to neonatal jaundice and neonatal intensive care unit admissions were more common in the neonates of T1DM mothers (Table 2).

Fetal heart rate was higher in T1DM fetuses. Ventricular and interventricular septal enddiastolic wall thicknesses were increased in the T1DM group when compared to controls. Both weight-adjusted right and left ventricular stroke volumes and cardiac outputs, as well as combined cardiac output were lower in the T1DM group fetuses than in the control group. The left ventricular isovolumic relaxation and contraction times, and the index of myocardial performance did not differ between the groups. However, mitral valve E/A-ratio was lower in the T1DM group fetuses compared to the controls. Pulsatility indices in the aortic isthmus and inferior vena cava were greater in the T1DM than in the control fetuses (Figure 1, Table 3). Pulsatility indices in other arteries and veins did not differ between the groups. Aortic isthmus pulsatility index values correlated positively $(R(85)=0.532,95 \%$ confidence interval $(C I) 0.368-0.754, p<0.001)$ with branch pulmonary artery pulsatility index values. Tricuspid valve E/A-ratio correlated negatively with right ventricular wall $(R(58)=-0.293,95 \% \mathrm{CI}-0.479$ to $-0.037, \mathrm{p}=0.023)$ and interventricular 
septal $(\mathrm{R}(58)=-0.257,95 \% \mathrm{CI}-0.449$ to $-0.002, \mathrm{p}=0.048)$ thicknesses. In the control group, no significant correlation was found between gestational age and any of the cardiovascular parameters (data not shown).

The newborn umbilical cord serum concentrations of NT-proANP, NT-proBNP, and TnT were significantly higher in the T1DM than in the control group. Placental IL and tumor necrosis factor alfa levels were comparable between the groups (Table 4). Umbilical artery pulsatility index values correlated positively with NT-proBNP, and left ventricular cardiac output correlated negatively with umbilical cord serum TnT concentration. Aortic isthmus pulsatility index values showed positive correlations with NT-proANP, NT-proBNP and TnT concentrations in the umbilical cord serum (Table 5). Mode of delivery did not affect any of the measured newborn serum biomarker concentrations or placental cytokine levels.

Inter- and intraobserver variabilities for left ventricular stroke volume were $2.4 \%$ and 3.5 $\%(95 \%$ CI, $0.9-5.2 \%)$. Interobserver variability for ductus venosus pulsatility index for veins was $5.3 \%(95 \%$ CI, $1.5-10.1 \%)$.

\section{DISCUSSION}

Maternal T1DM affects the fetal heart by increasing its wall thicknesses. In addition, weight-adjusted stroke volumes and cardiac outputs were decreased in the T1DM group at near term gestation. A significant positive correlation between the aortic isthmus and branch pulmonary artery pulsatility index values suggests that fetal pulmonary circulation has an important role in the maintenance of left ventricular cardiac output and aortic isthmus hemodynamics. On the other hand, placental vascular impedance was not compromised and there was no evidence of placental inflammation in maternal T1DM pregnancies.

In maternal T1DM, we found increased fetal myocardial wall thicknesses as demonstrated previously. ${ }^{4,14}$ In experimental studies, high maternal glucose concentrations directly increase fetal cardiac septal growth. ${ }^{20}$ However, increased fetal interventricular septal thickness is found also in T1DM mothers with good glycemic control. ${ }^{21}$ We observed that fetal weight-adjusted right and left ventricular stroke volumes and outputs, and mitral valve E/A-ratio were decreased. Furthermore, we found negative correlations between cardiac wall thicknesses and tricuspid valve E/A-ratio. Our findings suggest that the excess cardiac wall thickness may affect the active relaxation process of the myocardium. Our findings are supported by a previous study 
demonstrating that in diabetic pregnancies fetal biventricular diastolic dysfunction is present during the third trimester of pregnancy. ${ }^{22}$ Thus, it seems that at near term gestation, fetal left ventricular filling is more dependent on atrial contraction in maternal T1DM pregnancies.

However, the other indices of left ventricular function were comparable to the control group suggesting that functional disturbances could be rather subtle.

We found increased pulsatility of inferior vena cava blood flow velocity waveform in T1DM group fetuses, while ductus venosus pulsatility index for veins values were comparable between the groups. An increase in the pulsatility of systemic venous or ductus venosus blood flow profile could indicate elevated ventricular end-diastolic pressure and a rise in systemic venous pressure. Another cause is augmented atrial contraction that would be the most likely explanation in our study. Our findings suggest that inferior vena cava blood flow profile could be more sensitive than ductus venosus to changes in cardiac function, at least in maternal T1DM pregnancies. It must be kept in mind that ductus venosus blood flow profile is also affected by the amount of umbilical venous blood return from the placenta and the caliber of ductus venosus that is mainly regulated by fetal $\mathrm{pO}_{2} .{ }^{23}$

The pulsatility of fetal aortic isthmus blood flow velocity waveform was greater in T1DM pregnancies than in the controls at near term gestation. In fetal circulation, aortic isthmus has an important physiologic role allowing communication between the left and right ventricular outputs that are arranged in parallel. Aortic isthmus represents the arterial watershed between the upper (including brain) and lower (including placenta) body circulations. ${ }^{24}$ Normally, there is antegrade blood flow across the aortic isthmus towards the descending aorta throughout gestation. ${ }^{25} \mathrm{In}$ diastole, when the semilunar valves are closed, direction of blood flow across the aortic isthmus is mainly affected by cerebral and placental vascular resistances. ${ }^{26}$ Adequate central hemodynamics, in specific left ventricular cardiac output, are important in maintaining antegrade flow across the aortic isthmus. In the present study, umbilical artery and middle cerebral artery pulsatility index values did not differ between the groups suggesting that the placental and cerebral vascular impedances were comparable between the groups. Importantly, we found a positive correlation between aortic isthmus and branch pulmonary artery pulsatility index values. In other words, pulmonary vasoconstriction was associated with increased pulsatility in the aortic isthmus blood flow velocity waveform. During pulmonary vasoconstriction fetal lung volume blood flow decreases thus reducing blood flow return to the left atrium and ventricle. Fetal sheep studies suggest that foramen ovale cannot substantially increase its volume blood flow. ${ }^{27}$ Our findings 
suggest that fetal lung circulation has an important role in the maintenance of left ventricular cardiac output and normal hemodynamics in the aortic isthmus.

In this study, umbilical cord serum natriuretic peptide and TnT concentrations were elevated in the maternal T1DM group thus confirming the observations of previous studies. ${ }^{4,16}$ We propose that increased circulating natriuretic peptide levels reflect increased myocardial mass rather than are markers of cardiac dysfunction, because natriuretic peptides regulate and prevent excess cardiomyocyte growth. ${ }^{28}$ Furthermore, BNP, and to a lesser extent ANP, are vasodilators that reduce cardiac afterload in the fetus. ${ }^{29}$ This is supported by the finding that NT-proBNP levels correlated with placental vascular impedance. Our results suggest that fetal weight-adjusted systemic vascular resistance is increased in T1DM pregnancies, because fetal combined cardiac output was significantly lower than in the control group. In addition, TnT that is considered as a cardio-specific marker of myocardial cell damage ${ }^{5}$, had a negative correlation with left ventricular cardiac output further strengthening the concept that increased myocardial cell mass has a negative impact on ventricular function, i.e. producing adequate cardiac output. Finally, aortic isthmus pulsatility index values correlated with cardiac natriuretic peptide and TnT secretions demonstrating that aortic isthmus blood flow pattern can reflect alterations in fetal cardiac performance.

In T1DM pregnancies, umbilical artery vascular impedance was not different from the control group suggesting that functional capacity of placental tertiary villous arterioles was adequate and comparable to the control pregnancies. Furthermore, no evidence of placental inflammation was noted in T1DM pregnancies. One limitation of our study is that we did not perform any placental histologic examination. Previously, histological abnormalities in the placenta have been observed in T1DM pregnancies. In an experimental rat model of untreated maternal pregestational hyperglycemia, fetal cardiac hyperplasia and dysfunction, abnormal expression of cardiac and placental genes, and signs of placental insufficiency were seen at near term gestation. ${ }^{11,30}$ This could indicate that adequate glycemic control during pregnancy could prevent placental abnormalities, at least to certain degree.

Intra- and interobserver variabilities tested in this study were comparable to previous studies on volumetric blood flows. ${ }^{31}$ Fetal ultrasound was performed at an earlier gestational age in the T1DM group than in the controls and this could be a confounding factor. However, fetal hemodynamic parameters remain relatively constant throughout the third trimester ${ }^{32}$. In addition, we found no significant correlation between gestational age and any of the measured 
cardiovascular parameter during the third trimester of pregnancy. Furthermore, we adjusted fetal cardiac output measurements for estimated fetal weight thus further minimizing the effect of fetal gestational age. One of the strengths of this study is that we used several methods and approaches to assess fetal well-being and placental function. Another strength is that we recruited our diabetic patients consecutively thus minimizing any selection bias.

\section{CONCLUSION}

This study was designed to investigate fetal cardiovascular and placental function and hemodynamics in maternal T1DM pregnancies at near term gestation. The most important finding was that in maternal diabetes, fetal cardiovascular hemodynamics is impaired, including decreased cardiac output and increased pulsatility in the aortic isthmus blood flow velocity waveform. On the other hand, placental hemodynamics is maintained with no evidence of placental inflammation.

\section{References}

1. Han J, Xu J, Long YS, Epstein PN, Liu YQ. Rat maternal diabetes impairs pancreatic betacell function in the offspring. Am J Physiol Endocrinol Metab. 2007;293:E228-36.

2. Higgins M, Mc Auliffe F. A review of maternal and fetal growth factors in diabetic pregnancy. Curr Diabetes Rev. 2010;6:116-25.

3. Sandgren J, Scholz TD, Segar JL. ANG II modulation of cardiac growth and remodeling in immature fetal sheep. Am J Physiol Integr Comp Physiol. 2015;308:R965-72.

4. Russell NE, Higgins MF, Amaruso M, Foley M, McAuliffe FM. Troponin T and pro-Btype natriuretic Peptide in fetuses of type 1 diabetic mothers. Diabetes Care. 2009;32:2050 5.

5. Nomura RM, Cabar FR, Costa VN, Miyadahira S, Zugaib M. Cardiac troponin T as a biochemical marker of cardiac dysfunction and ductus venosus Doppler velocimetry. Eur J Obstet Gynecol Reprod Biol. 2009;147:33-6.

6. Zhang F, Xiao X, Liu D, Dong X, Sun J, Zhang X. Increased cord blood angiotensin II concentration is associated with decreased insulin sensitivity in the offspring of mothers with gestational diabetes mellitus. J Perinatol. 2013;33:9-14. 
7. Tennant PWG, Glinianaia S V, Bilous RW, Rankin J, Bell R. Pre-existing diabetes, maternal glycated haemoglobin, and the risks of fetal and infant death: a population-based study. Diabetologia. 2014;57:285-94.

8. Milley JR, Papacostas JS, Tabata BK. Effect of insulin on uptake of metabolic substrates by the sheep fetus. Am J Physiol. 1986;251:E349-56.

9. Jauniaux E, Burton GJ. Villous histomorphometry and placental bed biopsy investigation in Type I diabetic pregnancies. Placenta. 2006;27:468-74.

10. Nelson SM, Coan PM, Burton GJ, Lindsay RS. Placental structure in type 1 diabetes: relation to fetal insulin, leptin, and IGF-I. Diabetes. 2009;58:2634-41.

11. Lehtoranta L, Vuolteenaho O, Laine J, Polari L, Ekholm E, Räsänen J. Placental structural abnormalities have detrimental hemodynamic consequences in a rat model of maternal hyperglycemia. Placenta. 2016;44:54-60.

12. Alfirevic Z, Stampalija T, Gyte GML. Fetal and umbilical Doppler ultrasound in high-risk pregnancies. Cochrane Database Syst Rev. 2013;11:CD007529.

13. Kulkarni A, Li L, Craft M, Nanda M, Lorenzo JMM, Danford D, et al. Fetal myocardial deformation in maternal diabetes mellitus and obesity. Ultrasound ObstetGynecol. 2017;49:630-6.

14. Jaeggi ET, Fouron JC, Proulx F. Fetal cardiac performance in uncomplicated and wellcontrolled maternal type I diabetes. Ultrasound Obstet Gynecol. 2001;17:311-5.

15. El-Ganzoury MM, El-Masry SA, El-Farrash RA, Anwar M, Abd Ellatife RZ. Infants of diabetic mothers: echocardiographic measurements and cord blood IGF-I and IGFBP-1. Pediatr Diabetes. 2012;13:189-96.

16. Girsen A, Ala-Kopsala M, Makikallio K, Vuolteenaho O, Rasanen J. Increased fetal cardiac natriuretic peptide secretion in type-1 diabetic pregnancies. Acta Obstet Gynecol Scand. 2008;87:307-12.

17. Maruotti GM, Rizzo G, Sirico A, Sarno L, Cirigliano L, Arduini D, et al. Are there any relationships between umbilical artery Pulsatility Index and macrosomia in fetuses of type I diabetic mothers? J Matern Fetal Neonatal Med. 2014;27:1776-81.

18. Hernandez-Andrade E, López-Tenorio J, Figueroa-Diesel H, Sanin-Blair J, Carreras E, 
Cabero L, et al. A modified myocardial performance (Tei) index based on the use of valve clicks improves reproducibility of fetal left cardiac function assessment. Ultrasound Obstet Gynecol. 2005;26:227-32.

19. Ala-Kopsala M, Magga J, Peuhkurinen K, Leipälä J, Ruskoaho H, Leppäluoto J, et al. Molecular heterogeneity has a major impact on the measurement of circulating N-terminal fragments of A- and B-type natriuretic peptides. Clin Chem. 2004;50:1576-88.

20. Gordon EE, Reinking BE, Hu S, Yao J, Kua KL, Younes AK, et al. Maternal Hyperglycemia Directly and Rapidly Induces Cardiac Septal Overgrowth in Fetal Rats. J Diabetes Res. 2015;2015:479565.

21. Aman J, Hansson U, Ostlund I, Wall K, Persson B. Increased fat mass and cardiac septal hypertrophy in newborn infants of mothers with well-controlled diabetes during pregnancy. Neonatology. 2011;100:147-54.

22. Miranda JO, Cerqueira RJ, Ramalho C, Areias JC, Henriques-Coelho T. Fetal Cardiac Function in Maternal Diabetes: A Conventional and Speckle-Tracking Echocardiographic Study. J Am Soc Echocardiogr. 2018;31:333-41.

23. Ferrazzi E, Lees C, Acharya G. The controversial role of the ductus venosus in hypoxic human fetuses. Acta Obstet Gynecol Scand. 2019;98:823-9.

24. Kiserud T, Acharya G. The fetal circulation. Prenat Diagn. 2004;24:1049-59.

25. Ruskamp J, Fouron JC, Gosselin J, Raboisson MJ, Infante-Rivard C, Proulx F. Reference values for an index of fetal aortic isthmus blood flow during the second half of pregnancy. Ultrasound Obstet Gynecol. 2003;21:441-444.

26. Fouron J-C. The unrecognized physiological and clinical significance of the fetal aortic isthmus. Ultrasound Obstet Gynecol. 2003;22:441-7.

27. Hashima JN, Rogers V, Langley SM, Ashraf M, Sahn DJ, Ohtonen P, et al. Fetal ventricular interactions and wall mechanics during ductus arteriosus occlusion in a sheep model. Ultrasound Med Biol. 2015;41:1020-8.

28. Oliver PM, Fox JE, Kim R, Rockman HA, Kim HS, Reddick RL, et al. Hypertension, cardiac hypertrophy, and sudden death in mice lacking natriuretic peptide receptor A. Proc Natl Acad Sci U S A. 1997;94:14730-5. 
29. Cameron VA, Ellmers LJ. Minireview: natriuretic peptides during development of the fetal heart and circulation. Endocrinology. 2003;144:2191-4.

30. Lehtoranta L, Vuolteenaho O, Laine VJ, Koskinen A, Soukka H, Kytö V, et al. Maternal hyperglycemia leads to fetal cardiac hyperplasia and dysfunction in a rat model. Am $\mathrm{J}$ Physiol Endocrinol Metab. 2013;305:E611-9.

31. Mäkikallio K, Jouppila P, Räsänen J. Retrograde aortic isthmus net blood flow and human fetal cardiac function in placental insufficiency. Ultrasound Obstet Gynecol. 2003;22:3517.

32. Kiserud T, Rasmussen S, Skulstad S. Blood flow and the degree of shunting through the ductus venosus in the human fetus. Am J Obstet Gynecol. 2000;182:147-53.

This article is protected by copyright. All rights reserved 


\section{Figure and table legends.}

Figure 1. Aortic isthmus blood flow velocity waveforms. In upper panel, a waveform from a control group fetus that shows a normal small early-diastolic retrograde component and antegrade diastolic flow (arrow). In lower panel, a waveform from a type 1 diabetes mellitus group fetus demonstrating increased pulsatility in the blood flow profile. Early-diastolic retrograde component is larger and diastolic flow is retrograde.

Table 1. Maternal characteristics.

T1DM, type 1 diabetes mellitus; gHbA1c\%, glycated hemoglobin content; White B, diabetes onset age 20 y or older and duration less than $10 \mathrm{y}$; White $\mathrm{C}$, onset age 10-19 y or duration 10-19 y; White $\mathrm{D}$, onset age younger than $10 \mathrm{y}$ and duration over $20 \mathrm{y}$ with backround retinopathy or hypertension; White R, proliferative retinopathy or vitreous hemorrhage; White F, nephropathy.

Data are means $\pm \mathrm{SD}$, medians [range], or no of cases $(\%)$.

Table 2. Pregnancy outcome.

T1DM, type 1 diabetes mellitus; GA, gestational age; IUGR, intrauterine growth restriction; LGA, large for gestational age; NICU, neonatal intensive care unit.

Data are means $\pm \mathrm{SD}$, or no of cases $(\%)$.

Table 3. Hemodynamic data of the study groups

T1DM, type 1 diabetes mellitus; FHR, fetal heart rate; TV E/A-ratio, tricuspid valve E- to A-wave ratio; MV E/Aratio, mitral valve E- to A-wave ratio; RV, right ventricle; RVCO, RV cardiac output; LV, left ventricle; LVCO, LV cardiac output; CCO, combined cardiac output, IMP, index of myocardial performance; IRT\%, proportion of isovolumic relaxation time of the total cardiac cycle; ICT\%, proportion of isovolumic contraction time of the total cardiac cycle; RVW, right ventricular wall thickness; IVS, interventricular septum thickness; LVW, left ventricular wall thickness; UA, umbilical artery; PI, pulsatility index; MCA, middle cerebral artery; AoI, aortic isthmus; DAo, ductus arteriosus; BPA, branch pulmonary artery; IVC, inferior vena cava; DV, ductus venosus.

Data are means \pm SD.

This article is protected by copyright. All rights reserved 
Table 4. Umbilical cord blood and placental sample data.

T1DM, type 1 diabetes mellitus; NT-proANP, N-terminal peptide of proatrial natriuretic peptide; NT-proBNP, Nterminal peptide of proB-type natriuretic peptide; TnT, cardiac troponin T; IL, interleukin; TNF $\alpha$, tumor necrosis factor $\alpha$.

Data are means \pm SD.

Table 5. Correlations between fetal cardiovascular parameters and newborn serum concentrations of cardiac natriuretic peptides and troponin $\mathrm{T}$.

NT-proANP, N-terminal peptide of proatrial natriuretic peptide; NT-proBNP, N-terminal peptide of proB-type natriuretic peptide; TnT, cardiac troponin T; RVCO, right ventricular cardiac output; LVCO, left ventricular cardiac output; UA, umbilical artery; PI, pulsatility index; AoI, aortic isthmus; BPA, branch pulmonary artery; IVC, inferior vena cava; PIV, PI for veins; DV, ductus venosus.

Data are R (Pearson's correlation coefficient) with 95\% confidence interval (CI).

This article is protected by copyright. All rights reserved 


\begin{tabular}{|c|c|c|c|}
\hline Table 1. Maternal characteristics & & & \\
\hline Variable & Control & T1DM & $p$ \\
\hline $\mathbf{n}$ & 67 & 33 & \\
\hline Maternal pregnancy characteristics & & & \\
\hline Maternal age (years) & $28.0 \pm 4.0$ & $28.5 \pm 4.9$ & 0.620 \\
\hline Prepregnancy BMI (kg/m2) & $23.2 \pm 3.4$ & $26.1 \pm 4.9$ & NA \\
\hline Smoking & $2(3.0)$ & $5(15.2)$ & $<0.0001$ \\
\hline Nulliparous & $42(62.7)$ & $17(15.5)$ & 0.173 \\
\hline White class & & & \\
\hline B & & $6(18.2)$ & NA \\
\hline $\mathrm{C}$ & & $8(24.2)$ & NA \\
\hline $\mathrm{D}$ & & $6(18.2)$ & NA \\
\hline $\mathrm{R}$ & & $8(24.2)$ & NA \\
\hline$F, D+R, R+F$ & & $6(18.2)$ & NA \\
\hline $\mathrm{gHbA} 1 \mathrm{c} \%$ & & $7.9 \pm 1.2$ & NA \\
\hline Hypertension & $3(4.5)$ & $5(15.2)$ & 0.027 \\
\hline Pregnancy characteristics & & & \\
\hline gHbA1c\% (32 weeks) & & $6.4 \pm 0.9$ & NA \\
\hline Incidence of hypoglycemia $(<2,6 \mathrm{mmol} / \mathrm{I})$ & & $15(45.5)$ & NA \\
\hline Basal insulin dose (30 weeks) & & $49.0 \pm 20.5$ & NA \\
\hline Prandial insulin dose ( 30 weeks) & & $42.6 \pm 19.5$ & NA \\
\hline Retinopathy during pregnancy & & $20(60.6)$ & NA \\
\hline Nephro- or neuropathy & & $6(18.2)$ & NA \\
\hline Hypertension or pre-eclampsia & $6(9.0)$ & $11(23.3)$ & 0.010 \\
\hline
\end{tabular}

T1DM, type 1 diabetes mellitus; gHbA1c\%, glycated hemoglobin content; White $B$, diabetes onset age 20 y or older and duration less than $10 \mathrm{y}$; White $C$, onset age 10-19 y or duration 10-19 y; White $D$, onset age younger than $10 \mathrm{y}$ and duration over $20 \mathrm{y}$ with backround retinopathy or hypertension; White $\mathrm{R}$, proliferative retinopathy or vitreous hemorrhage; White $F$, nephropathy.

Data are means $\pm S D$, medians [range], or no of cases (\%). 


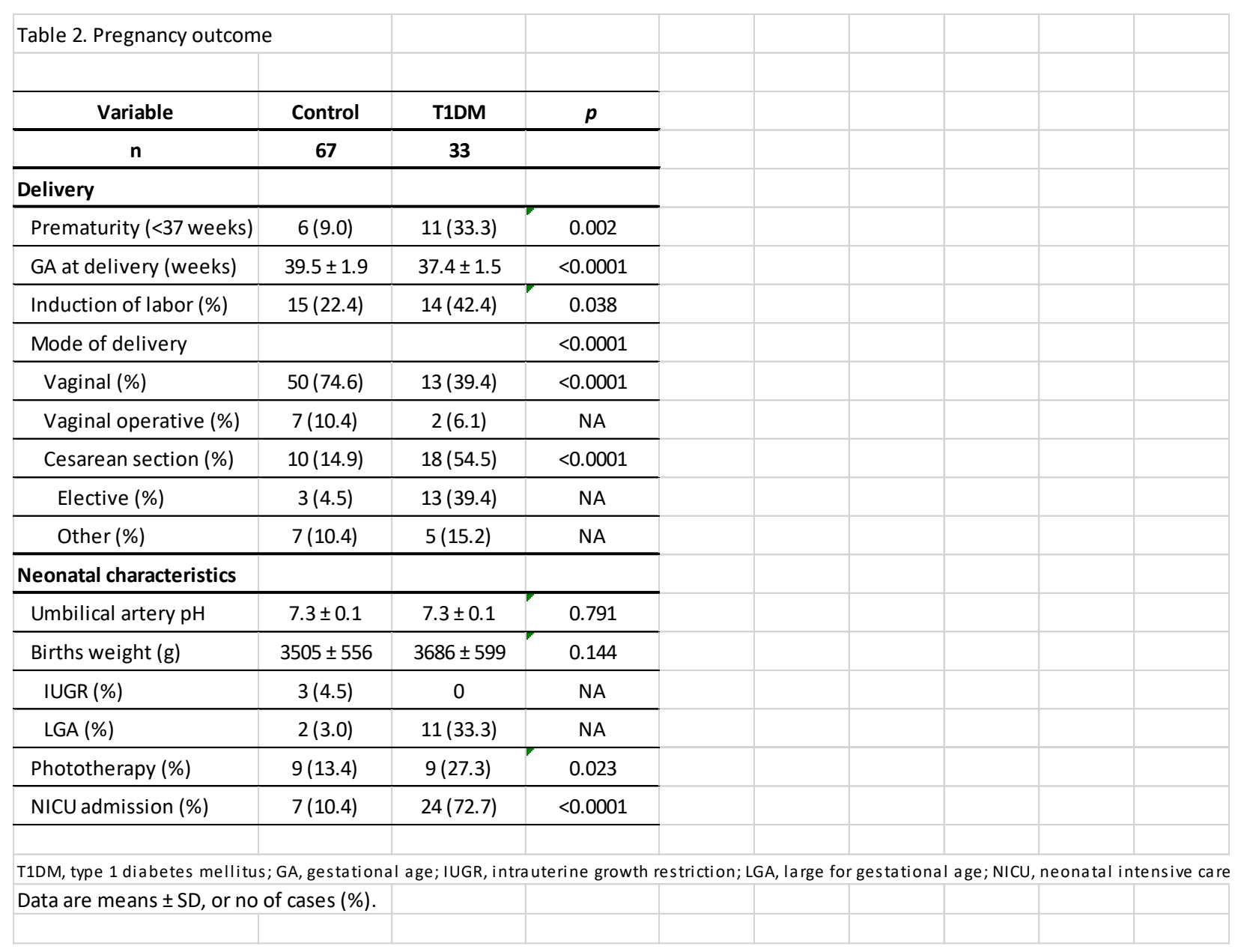


Table 3. Hemodynamic data of the study groups

\begin{tabular}{|c|c|c|c|}
\hline Variable & Control & T1DM & $p$ \\
\hline $\mathbf{n}$ & 67 & 33 & \\
\hline Gestational week & $37+3 \pm 1+6$ & & \\
\hline \multicolumn{4}{|l|}{ Central hemodynamics } \\
\hline FHR (bpm) & $137.4 \pm 10.7$ & $144.3 \pm 13.4$ & 0.007 \\
\hline TV E/A-ratio & $0.66 \pm 0.22$ & $0.63 \pm 0.30$ & 0.537 \\
\hline MV E/A-ratio & $0.83 \pm 0.29$ & $0.66 \pm 0.27$ & 0.006 \\
\hline RV stroke volume (ml) & $3.19 \pm 1.16$ & $2.47 \pm 1.32$ & 0.009 \\
\hline $\mathrm{RVCO}\left(\mathrm{ml} / \mathrm{min}^{*} \mathrm{~kg}\right)$ & $369.1 \pm 85.5$ & $220.1 \pm 93.4$ & $<0.0001$ \\
\hline LV stroke volume (ml) & $2.09 \pm 0.78$ & $1.71 \pm 0.85$ & 0.024 \\
\hline LVCO (ml/min*kg) & $247.9 \pm 61.5$ & $162.3 \pm 65.9$ & $<0.0001$ \\
\hline $\mathrm{CCO}\left(\mathrm{ml} / \mathrm{min}^{*} \mathrm{~kg}\right)$ & $619.2 \pm 129.5$ & $405.9 \pm 184.5$ & 0.001 \\
\hline IMP (LV) & $0.43 \pm 0.10$ & $0.43 \pm 0.09$ & 0.775 \\
\hline IRT \% & $10.5 \pm 2.8$ & $10.4 \pm 2.0$ & 0.856 \\
\hline ICT \% & $6.7 \pm 2.3$ & $6.3 \pm 1.9$ & 0.376 \\
\hline RVW diastole (mm) & $3.5 \pm 0.6$ & $5.6 \pm 2.6$ & $<0.0001$ \\
\hline IVS diastole $(\mathrm{mm})$ & $3.5 \pm 0.9$ & $5.8 \pm 3.0$ & $<0.0001$ \\
\hline LVW diastole $(\mathrm{mm})$ & $3.5 \pm 0.7$ & $4.5 \pm 0.8$ & $<0.0001$ \\
\hline \multicolumn{4}{|l|}{ Pregnancy characteristics } \\
\hline UA PI & $0.88 \pm 0.20$ & $0.73 \pm 0.41$ & 0.135 \\
\hline MCA PI & $1.58 \pm 0.47$ & $1.67 \pm 0.71$ & 0.372 \\
\hline Aol PI & $3.77 \pm 0.76$ & $7.23 \pm 4.42$ & 0.025 \\
\hline DAo PI & $1.97 \pm 0.44$ & $1.92 \pm 0.41$ & 0.316 \\
\hline BPA PI & $4.51 \pm 1.73$ & $6.08 \pm 2.64$ & 0.281 \\
\hline IVCPIV & $1.70 \pm 0.43$ & $2.01 \pm 0.34$ & 0.001 \\
\hline DV PIV & $0.50 \pm 0.18$ & $0.53 \pm 0.10$ & 0.746 \\
\hline
\end{tabular}

T1DM, type 1 diabetes mellitus; FHR, fetal heart rate; TV E/A-ratio, tricuspid valve E- to A-wave ratio; MV E/A-ratio, mitral valve E- to A-wave ratio; RV, right ventricle; RVCO, RV cardiac output; LV, left ventricle; LVCO, LV cardiac output; CCO, combined cardiac output, IMP, index of myocardial performance; IRT\%, proportion of isovolumic relaxation time of the total cardiac cycle; ICT\%, proportion of isovolumic contraction time of the total cardiac cycle; RVW, right ventricular wall thickness; IVS, interventricular septum thickness; LVW, left ventricular wall thickness; UA, umbilical artery; PI, 
pulsatility index; MCA, middle cerebral artery; Aol, aortic isthmus; DAo, ductus arteriosus; BPA, branch pulmonary artery; IVC, inferior vena cava; DV, ductus venosus.

Data are means \pm SD.

Table 4. Umbilical cord blood and placental sample data.

\begin{tabular}{|c|c|c|c|}
\hline & & & \\
\hline Variable & Control & T1DM & $\boldsymbol{p}$ \\
\hline Umbilical cord blood & & & \\
\hline $\mathbf{n}$ & $\mathbf{6 7}$ & $\mathbf{3 3}$ & \\
\hline NT-proANP (pmol/I) & $2134.0 \pm 945.6$ & $2956.7 \pm 1304.4$ & 0.003 \\
\hline NT-proBNP (pmol/I) & $383.8 \pm 267.7$ & $710.4 \pm 488.4$ & $<0.0001$ \\
\hline TnT (ng/ml) & $0.014 \pm 0.008$ & $0.033 \pm 0.032$ & $<0.0001$ \\
\hline Placenta & & & \\
\hline & $\mathbf{2 5}$ & $\mathbf{2 4}$ & \\
\hline IL13 (pg/mg prot) & $<6.58$ & $<6.58$ & NA \\
\hline IL6 $(\mathrm{pg} / \mathrm{mg}$ prot) & $20.63 \pm 29.44$ & $31.89 \pm 77.61$ & 0.558 \\
\hline IL10 $(\mathrm{pg} / \mathrm{mg}$ prot) & $<7.08$ & $<7.08$ & NA \\
\hline TNF $\alpha$ (pg/mg prot) & $6.13 \pm 0.46$ & $6.18 \pm 0.78$ & 0.767 \\
\hline
\end{tabular}

T1DM, type 1 diabetes mellitus; NT-proANP, N-terminal peptide of proatrial natriuretic peptide; NTproBNP, N-terminal peptide of proB-type natriuretic peptide; $\mathrm{TnT}$, cardiac troponin $\mathrm{T}$; IL, interleukin; TNF $\alpha$, tumor necrosis factor $\alpha$.

Data are means \pm SD.

Table 5. Correlations between fetal cardiovascular parameters and newborn serum concentrations of cardiac natriuretic peptides and troponin T.

\begin{tabular}{l|c|c|c|c|c|c}
\hline Variable & \multicolumn{2}{|c|}{ NT-proANP (pmol/I) } & \multicolumn{2}{c|}{ NT-proBNP (pmol/l) } & \multicolumn{2}{c}{ TnT (ng/ml) } \\
\hline & $\mathrm{R}(95 \% \mathrm{Cl})$ & $p$ & $\mathrm{R}(95 \% \mathrm{Cl})$ & $p$ & $\mathrm{R}(95 \% \mathrm{Cl})$ & $p$ \\
\hline RVCO $\left(\mathrm{ml} / \mathrm{min}^{*} \mathrm{~kg}\right)$ & $0.936(-0.31-0.51)$ & 0.171 & $-0.018(-0.36-0.67)$ & 0.903 & $-0.212(-0.19-0.25)$ & 0.153 \\
\hline LVCO (ml/min*kg) & $-0.171(-0.43-0.36)$ & 0.231 & $-0.187(-0.62-0.34)$ & 0.189 & $-0.364(-0.22-0.19)$ & 0.009 \\
\hline UA PI & $0.217(0.23-1.09)$ & 0.051 & $0.279(0.40-1.43)$ & 0.011 & $-0.118(-0.34-0.10)$ & 0.290 \\
\hline Aol PI & $0.259(-0.44-2.23)$ & 0.020 & $0.240(-0.65-2.56)$ & 0.032 & $0.454(-0.27-1.10)$ & $<0.0001$ \\
\hline BPA PI & $0.019(-0.27-0.43)$ & 0.873 & $0.094(-0.21-0.63)$ & 0.414 & $0.171(-0.26-0.10)$ & 0.137 \\
\hline IVC PIV & $0.173(-0.15-0.38)$ & 0.135 & $0.177(-0.15-0.49)$ & 0.125 & $0.057(-0.19-0.09)$ & 0.623 \\
\hline DV PIV & $0.127(0.04-0.80)$ & 0.277 & $0.312(0.19-1.11)$ & 0.254 & $0.017(-0.19-0.20)$ & 0.887 \\
\hline
\end{tabular}


NT-proANP, N-terminal peptide of proatrial natriuretic peptide; NT-proBNP, N-terminal peptide of proBtype natriuretic peptide; TnT, cardiac troponin T; RVCO, right ventricular cardiac output; LVCO, left ventricular cardiac output; UA, umbilical artery; PI, pulsatility index; Aol, aortic isthmus; BPA, branch pulmonary artery; IVC, inferior vena cava; PIV, PI for veins; DV, ductus venosus.

Data are R (Pearson's correlation coefficient) with 95\% confidence interval (Cl). 


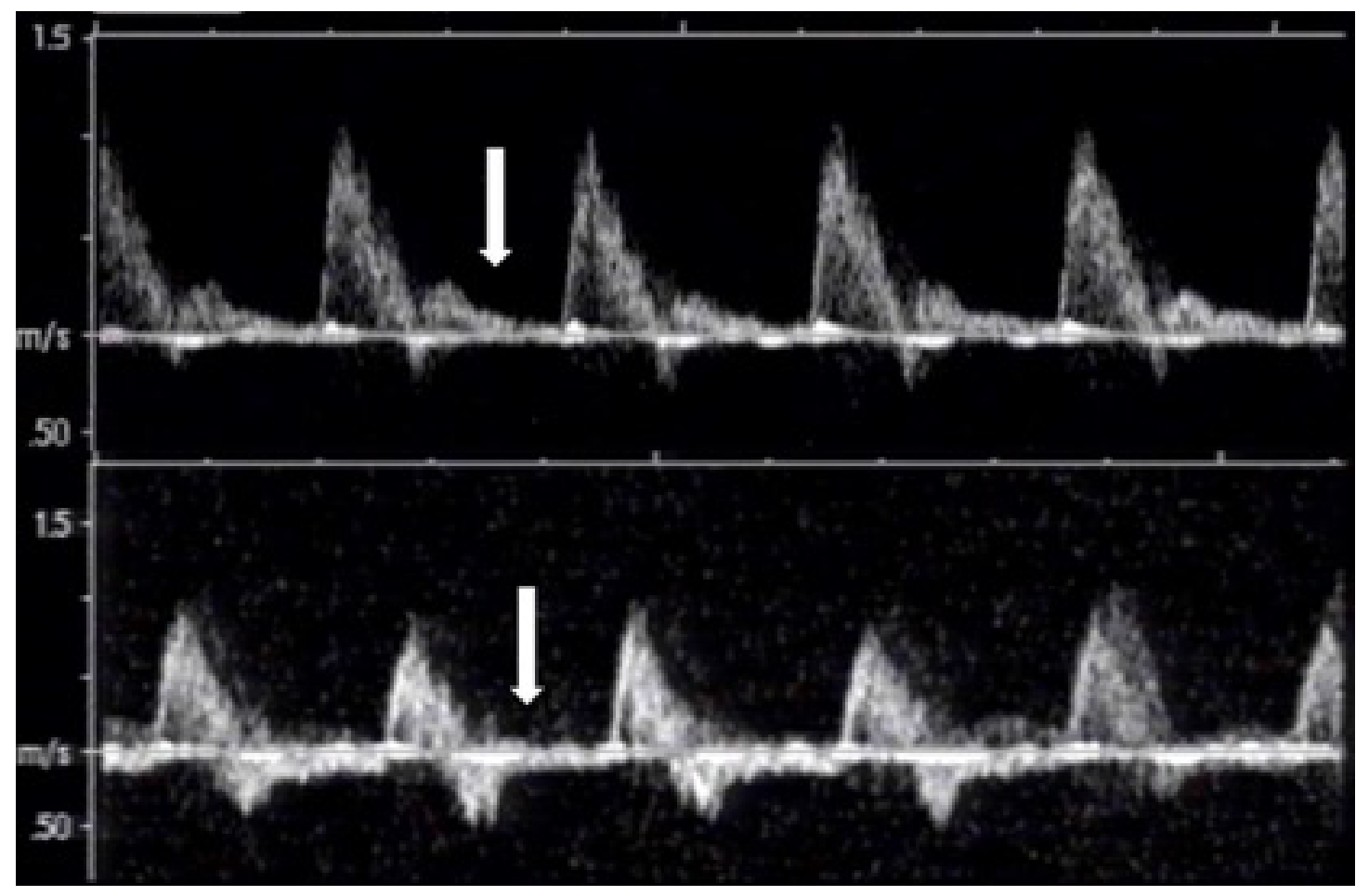

aogs_13987_f1.tiff 